Archived version from NCDOCKS Institutional Repository http://libres.uncg.edu/ir/asu/

Williams, Marian. (2013). The effectiveness of public defenders in four Florida counties. Journal of Criminal Justice, 41:4, July-August 2013, pages 205-212. Version of record available from Elsevier. [ISSN: 0047-2352], [doi:10.1016/j.jcrimjus.2013.05.004].

\title{
The effectiveness of public defenders in four Florida counties
}

\author{
Marian R. Williams
}

\begin{abstract}
The present study utilizes data from the Bureau of Justice Statistics to examine the effectiveness of public defenders in Florida to assess whether the case outcomes of defendants with public defenders are similar to the case outcomes of defendants with retained attorneys, controlling for legally-relevant variables. Methods: The present study utilizes both logistic and OLS regression analysis to examine differences between attorneys for seven different case outcomes. Results: Results indicate that defendants with public defenders are more likely to be detained pretrial, more likely to be convicted, and less likely to have their cases dismissed. The results dispute previous research which found few, if any, differences between public defenders and retained counsel. Conclusion: Results suggest that, at least in the counties examined, defendants with public defenders suffer from a lack of quality counsel.
\end{abstract}

\section{Introduction}

The right to assistance of counsel is found within the Sixth Amendment to the Constitution, although the actual practice of defending clients only encompassed those who could afford to pay for counsel (Garcia, 1992 ). Due to this, until the 20th century, many defendants within the criminal justice system had no counsel to represent them and the states and the federal government routinely did not provide assistance. As a result of several U.S. Supreme Court cases, the right to appointed counsel was provided to many (though not all) defendants in the criminal justice system (see Powell v. Alabama, 287 U.S. 45, (1932); Gideon v. Wainwright, 372 U.S. 335, (1963); Argersinger v. Hamlin, 407 U.S. 25, (1972)). Today, it is estimated that approximately 80 percent of all criminal cases feature appointed counsel (Smith \& DeFrances, 1996; The Spangenberg Group, 2001). One of the mechanisms for providing appointed counsel is a public defender system, which features salaried attorneys working for a non-pro fi $t$ organization that provides indigent representation in criminal cases (Neubauer \& Fradella, 2011). Public defenders represent the bulk of indigent defendants among the appointed counsel 
systems (which include assigned counsel, contract systems, and legal aid), representing approximately 82 percent of indigents in the 100 most populous counties in the United States (Office of Justice Programs, 2011). At the federal level public defenders represent approximately 66 percent of indigent defendants (Wolf-Harlow, 2000). Given the state of case- loads in criminal courts, public defenders are taking on the bulk of indigent defense cases and keeping quite busy. The present study examines the relationship between type of attorney and various case outcomes, building upon recent studies (in particular, Williams, 2002; Hartley, Miller, \& Spohn, 2010 ), which assessed the effective- ness of public defenders and private attorneys in Florida and Illinois, respectively.

The representation provided by public defenders has been the subject of much scholarly discussion. In particular, scholars have considered whether defendants represented by public defenders receive the same type of representation (typically measured as case out-comes) as defendants with privately retained attorneys. In this research, there is speculation that perhaps public defenders are too busy to effectively represent their clients. A number of studies have assessed the impact of the use of a public defender on case outcomes. These outcomes include the likelihood of conviction, whether the defendant was convicted through a plea or a trial, and whether the defendant was sentenced to prison. The results of these studies are mixed. Some studies have found that there is little to no difference be-tween types of counsel when it comes to whether the defendant is convicted (Hanson \& Ostrom, 1998; Hermann et al., 1977; National Center for State Courts, 1992; Stover \& Eckhart, 1975; Taylor et al., 1973; WolfHarlow, 2000), whether the defendant pleads guilty or goes to trial (Nardulli, 1986; Taylor et al., 1973), whether the defendant is incarcerated (Hartley, Miller, \& Spohn, 2010; Lehtinen \& Smith, 1974; Spohn \& Holleran, 2000; Stover \& Eckhart, 1975; Williams, 2002), or the length of sentence (Hartley, Miller, \& Spohn, 2010; Williams, 2002; Wilson, 1984). Other studies have found that there is no relationship between type of attorney and bail decisions (Turner \& Johnson, 2007) or terms of plea agreements (Liang, Long \& Brame, 2012). Despite this, a number of studies have found differences with regard to type of attorney and its effect on case outcome.

Regarding likelihood of conviction, Silverstein (1965), in his examination of 11,000 cases in 194 counties, found that retained counsel had lower conviction rates than public defenders. This was supported in re-search by Nagel (1973), who found that defendants with retained counsel were more likely to be found not guilty. However, Hermann et al.(1977) found that, in some of their analyses (i.e., in Los Angeles), public defenders had lower conviction rates than retained counsel. More re-cent research by Anderson and Heaton (2012) found that defendants with public defenders had lower conviction rates than defendants with retained counsel. In federal courts, lyengar (2010) found that defendants with public defenders were less likely to be found guilty com-pared to court-appointed private attorneys (panel attorneys).

Regarding the relationship between type of attorney and whether the defendant pleads guilty or goes to trial, Gitelman (1971) noted that retained counsel clients had fewer guilty pleas. This is supported in research by Taylor et al. (1973), Champion (1989), and Anderson and Heaton (2012), who all found that defendants with public defenders were more likely to plead guilty.

Regarding incarceration, Gitelman (1971) found that defendants with retained counsel were less likely to be incarcerated than defendants with public defenders. This is supported in research by Hermann et al. (1977) and the National Center for State Courts (1992). Regarding length of sentence, Silverstein (1965) and Hoffman et al. (2005) indicated that defendants with retained 
counsel received lighter prison sentences. On the other hand, lyengar (2010) reports that, in federal courts, defendants with public defenders receive shorter sentences than defendants with court-appointed private counsel. In state courts, Anderson and Heaton (2012) found that defendants with public defenders receive less prison time than defendants with retained counsel.

For case outcomes other than conviction and sentencing, research is not as extensive. One of these outcomes, bail, is perhaps the most researched, but still not as much as conviction and sentencing variables. The research that has been done tends to find that public de-fenders do not secure as favorable bail outcomes for their clients as retained counsel. Farrell and Swigert (1978) found that retained counsel was more successful in securing bail than public defenders, while Holmes et al. (1996) and Turner and Johnson (2003) indicated that defendants with retained counsel were more likely to be released prior to trial. Regarding the amount of bail imposed, research by Turner and Johnson $(2006,2007)$ provides conflicting results. In 2006 , the authors found that defendants with public defenders had lower bail amounts set, while research in 2007 found that defendants with public defenders had higher bail amounts set. Regardless of the conflicting results, the few studies that examine the effect of attorney type on bail outcomes tend to show that retained counsel performs better than public defenders in this regard.

\section{Explanations for differences}

According to Calogero (1995), Weitzer (1996), and the Spangenberg Group (2009), many public defender organizations do not have adequate resources to prepare cases effectively; as a result, some attorneys in public defender offices suffer from burnout and from the perception that they are not adequately representing their clients (Ogletree, 1995). According to the Justice Policy Institute (2011),

[t]he defender systems that people must turn to are too often completely overwhelmed; many dedicated defenders simply have too many cases, too little time and too few resources to provide quality or even adequate legal representation... The defense receives less funding than the prosecution in many jurisdictions, leading to significant inequalities in resources and services to defend people who stand accused (p. 2, 8).

Joy (2010) indicates that excessive caseloads, lack of funds for expert witnesses and investigators, and low pay all contribute to ineffective representation by public defenders. As a result, defenders may cut corners by not meeting with their clients, not examining the case file thoroughly, or pressuring clients to plead guilty.

One way that public defenders can deal with their caseloads is to participate in the courtroom workgroup. As part of the workgroup, public defenders work with prosecutors and judges to negotiate an efficient end to cases coming into the system. Many of the resolutions involve plea agreements, with some arguing that that public defenders are quick to suggest and accept plea agreements in order to get cases off of their desks (see Albert-Goldberg \& Hartman, 1983). Due to this, a true adversarial process is not in place for defendants, who may become victims of their attorneys' haste. Retained attorneys who are not part of the courtroom workgroup may not have any interest in plea agreements, especially if their clients are willing to pay for their services. Also, retained attorneys may not have the case-load of public defenders, which can reduce their desire to negotiate and/or resolve a case quickly (Hartley, Miller, \& Spohn, 2010). 
Relatedly, some have argued that public defenders have been "co-opted" by the courtroom workgroup. Blumberg (1967) was one of the first to charge that public defenders work for the court system more so than defendants, in hopes of reducing their caseloads and getting a quick resolution their cases. Also, Eisenstein, Fleming, and Nardulli (1987) indicate that a public defender's relationship with the other members of the courtroom workgroup suggests that a public defender's main allegiance is with the court and not the client (see also Uphoff, 1992).

Despite this, others charge that a public defender's relationship with the other members of the courtroom workgroup actually benefits defendants. Because cooperation is key within the workgroup, public de-fenders are able to negotiate favorable outcomes for their clients and in a faster amount of time (Champion, 1989; Skolnick, 1967; Taylor et al., 1973). Stover and Eckhart (1975) state that public defenders and retained counsel have similar outcomes with regard to conviction odds. In fact, some suggest that defendants with public defenders may fare better than defendants with retained counsel regarding conviction rates and/or length of sentences (see Hermann et al., 1977). Anderson and Heaton (2012) speculate that more favorable outcomes for clients of public defenders could be attributed a desire to appease the workgroup and plead guilty, which would give their clients a better out-come than going to trial and suffering a potential trial penalty. Relatedly, lyengar (2010) states that public defenders have better negotiating abilities than their retained counterparts and are more adept at determining which cases to plead. Anderson and Heaton (2012) also point out that public defenders are successful at trial as well, in that their experience enables them to recognize "winners"-those whose cases are likely to result in an acquittal - and taking them to trial and winning. Finally, Anderson and Heaton (2012) argue that, at trial, public defenders may simply be better at arguing cases, giving them more favorable outcomes.

As one can see, previous research on the relationship between type of attorney and case outcomes is nebulous. Also, much of the previous research on the issue is quite dated; few of the studies listed were conducted after the year 2000. Also, a number of the studies are not adequately controlled (Silverstein, 1965; Gitelman, 1971; Nagel, 1973; Champion, 1989), so these studies should be viewed with caution. The present study seeks to build upon recent research (specifically, Williams, 2002; and Hartley, Miller, \& Spohn, 2010) with an assessment of the effectiveness of public defenders in the state of Florida.

\section{Methodology}

Data from the present study were taken from the Bureau of Justice Statistics State Court Processing Statistics, 1990-2006: Felony Defendants in Large Urban Counties provided by the Inter-University Consortium for Political and Social Research (ICPSR). The data contain information for felony cases filed in 40 of the 75 most populous counties in the United States, featuring arrest charges, demographic characteristics, criminal history, pretrial release and detention, adjudication, and sentencing. For the present study, four Florida counties are utilized for the year 2006. The four counties in Florida were among seven counties in Florida that were included in the data. The data cover the years 1990-2006. The reason for the use of four counties instead of seven is that the three excluded counties did not have consistent reporting for the variables in the study. Also, the reporting for all seven counties was inconsistent across the time periods; therefore, the year 2006 was chosen for two reasons. First, it is the most recent year included in the database, which makes for a more current examination of the issue. Second, the four included counties provided consistent and thorough reporting of data for the 
variables in the study. In addition, Florida was utilized to expand upon Williams (2002), who only examined a sample of cases in one Florida county.

Recently, Hartley, Miller, and Spohn (2010) indicate that previous research has not adequately addressed the effect of attorney type across a variety of case of case outcomes, especially outcomes that occur before a conviction results. In their study, Hartley, Miller, and Spohn (2010) assessed effect of attorney type on four case outcomes: pretrial status, reduction of charges, whether the defendant was sentenced to prison, and the mean prison length. In the present study, these and other case outcome variables are examined. The dataset enables the present study to examine six outcome variables encompassing both pre-conviction and conviction variables. It should be noted that Williams (2002) did not assess pretrial outcomes. Therefore, the present study combines an expansion of Williams (2002) with regard to Florida counties, as well as an expansion of Hartley, Miller, and Spohn (2010) with the use of more pretrial and conviction variables.

Florida utilizes a state-wide public defender system, in which each judicial circuit has a Head Public Defender, elected to a term of four years by the general public. Each judicial circuit has public defender offices in each county within the circuit. The Florida Supreme Court has noted that the Florida public defender system is underfunded, granting public defenders the ability to recuse themselves from cases due to overwhelming caseload (see Bennett v. State, 605 So. 2d 552, 1992; Woods v. State, 595 So. 2d 264, 1992; Denmark v. Florida,616So.2d, 1104, 1993). In a letter to then-Governor Jeb Bush, the president of the Florida Public Defender Association argued against statewide bud-get cuts proposed by Bush, arguing instead that Florida's public defender system needs more attorneys as well as higher pay for those attorneys in order to recruit and keep attorneys working in public defense. Due to the lack of resources, many public defenders resign their positions, citing burnout, and this led to multiple continuances, back-logs in dockets, and the appointment of private counsel to represent indigent defendants (Babb, 2000). Given the state of public defense in Florida, it is quite possible that case outcomes could be affected.

A number of dependent variables were utilized in the present study. These are addressed in turn below.

\section{Dependent variables}

The dependent variables were divided into pre-conviction and conviction variables. For the preconviction variables, the dependent variables were associated with dismissals and bail outcomes. Research examining the effect of type of attorney on the dismissal of charges is relatively rare, but was does exist suggests inconsistent results. Taylor et al. (1973) state that defendants with retained counsel had a higher rate of dismissals compared to defendants with public defenders. This was supported in research by Hanson and Ostrom (1998). However, Wice (2005) suggested that there is little difference between type of attorney regarding the dismissal of charges. Due to this inconsistency, developing a hypothesis does not seem prudent.

Therefore, this relationship can be viewed as an exploratory examination. This variable was coded as $0=$ not dismissed, 1 = dismissed (Dismiss). Williams (2002) and Hartley, Miller, and Spohn (2010) did not examine this variable. 
For other pre-conviction variables, the use of bail outcomes as de-pendent variables both replicates and expands upon Hartley, Miller, and Spohn (2010). Previous research indicates that retained attorneys are more successful in securing pre-trial release for their clients (Holmes et al., 1996; Nagel, 1973; Farrell \& Swigert, 1978). Due to this, hypotheses \#1 and \#2 are formulated:

\section{Hypothesis \#1. There is no relationship between type of attorney and whether a defendant is offered bail.}

\section{Hypothesis \#2. Defendants with public defenders are less likely to be released on bail than defendants with retained counsel.}

To test these hypotheses, three dependent variables were utilized. The first variable assessed whether the defendant was offered bail by the judge. This variable was coded as $0=$ no, $1=$ yes (BailOffer), a dichotomous variable. The second variable was whether the defendant was detained prior to case disposition. This variable is coded as $0=$ not detained, $1=$ detained (BailDet), a dichotomous variable. The use of these two variables is different than that used by Hartley, Miller, and Spohn (2010). These authors utilized one variable, pretrial status, as a measure. It was operationalized as a dichotomous variable, measuring whether the defendant was released or was detained/had bail set. In the present study, this variable is separated into two variables: one that asks if the defendant was offered bail and another that asks if the defendant was released or detained. Again, it should be noted that Williams (2002) did not examine pretrial outcomes.

For the conviction variables, a number of dependent variables were utilized. The conviction variables assess the case outcome for the defendant. One conviction variable is whether or not the defendant's charges were reduced from a felony to a misdemeanor. Hanson and Ostrom et al. (1998) found that type of attorney had no impact on whether a defendant's charges were reduced and this is supported by Hartley, Miller, and Spohn (2010). As a result, the following hypothesis was formulated:

\section{Hypothesis \#3. There is no relationship between type of attorney and likelihood of having charges dropped to a misdemeanor.}

This variable was measured as a dichotomous variable with $0=$ not dropped and $1=$ dropped (Misdemeanor). In the Hartley, Miller, and Spohn (2010) study, this variable simply asked whether the primary charge was reduced or, rather, whether the conviction charge was lower than the original filed charge. Williams (2002) did not examine this variable.

Another conviction variable is whether or not the defendant was convicted. Although Hanson and Ostrom (1998) and Wolf-Harlow (2000) state that conviction rates are similar for both retained counsel and public defenders, Silverstein (1965) noted that defendants with public defenders were more likely to be convicted than defendants with retained counsel. Since the most recent previous research asserts no relationship between public defenders and conviction, hypothesis \#4 is formulated:

\section{Hypothesis \#4. There is no relationship between type of attorney and likelihood of conviction.}

This variable was measured as a dichotomous variable with $0=$ not convicted and $1=$ convicted (Convict). Neither Williams (2002) nor Hartley, Miller, and Spohn (2010) measured this variable. 
Yet another conviction variable assesses whether or not a convicted defendant was sentenced to prison. Williams (2002), Hartley, Miller, and Spohn (2010) and Spohn and Holleran (2000) found that type of attorney had no effect on the odds of incarceration, but Gitelman (1971) found that defendants with retained counsel were less likely to receive incarceration. As with the conviction variable, since the most recent previous research indicates no relationship be-tween type of attorney and prison, hypothesis \#5 is formulated:

\section{Hypothesis \#5. There is no relationship between type of attorney and the likelihood of receiving a prison sentence.}

This variable was coded as $0=$ not sentenced to prison and $1=$ sentenced to prison (Prison), a dichotomous variable. This is consistent with Williams (2002) and Hartley, Miller, and Spohn (2010).

Finally, for those defendants sentenced to prison, the final conviction variable was how long the defendant was sentenced to prison. Williams (2002) found no relationship between type of attorney and sentence length and this was supported by Hartley, Miller, and Spohn (2010). However, Hoffman et al. (2005) did find significant differences between public defenders and retained counsel, in that defendants with public defenders were significantly more likely to receive longer prison sentences than defendants using retained counsel. Since the most recent research found no relationship and Williams (2002), utilizing Florida data, also found no relationship, hypothesis \#6 is formulated:

\section{Hypothesis \#6. There is no relationship between type of attorney and length of sentence.}

This variable was coded as the number of months the defendant was sentenced to prison (PrisonMonths) a continuous variable. This is consistent with Hartley, Miller, and Spohn (2010), although Williams (2002) assessed sentence length in days, not months.

It should be noted that one potential dependent variable, whether or not the defendant was convicted by a plea agreement or trial, was not examined in the present study. The data indicate that, during this time period, 98 percent of all convictions were garnered through plea agreements, resulting in little variability for this variable.

Independent variable

The primary variable of interest was type of attorney. This variable only assessed whether a defendant had a retained attorney or a public defender. All other types of appointed counsel were excluded in order to directly examine the effect of having a public defender versus retained counsel. This variable was coded as $0=$ retained, $1=$ public defender (Atty).

Control variables

Control variables include defendant and case characteristics, among others. These variables were examined based on previous research indicating their relationship to case outcomes. Defendant gender has been found to influence case outcomes (see Crow \& Gertz, 2009; Daly, 1987; Turner \& Johnson, 2006); thus, this variable was included and measured as $0=$ male, $1=$ female (Gender). Also, defendant age (continuous variable (Age)) was included due to prior research results indicating an effect on case outcome (see Spohn \& Holleran, 2000; Steffensmeier et al., 1998), as was defendant race (see Steffensmeier et al., 1998; Walker, Spohn, \& DeLone, 2004) The defendant's race includes two variables - whether the defendant 
was Black ( 0 = no, 1 = yes (DefBlack)) or Hispanic $(0=$ no, $1=$ yes (DefHisp). These were included in the analyses with White defendants as the reference category.

Offense characteristics feature the type of offense (e.g., violent, property, drug) and the total number of charges against the defendant. For the type of offense, two variables were utilized. Those whose primary charge was a property offense were coded as $0=$ non-property, $1=$ property (Property) and those whose primary charge was a drug offense were coded as $0=$ non-drug, 1 = drug (Drug). Violent offenses served as the reference category for this analysis due to previous research indicating that serious, violent offenders are more likely to be treated punitively compared to other offenders (see Hartley, Miller, \& Spohn, 2010; Spohn \& Katz, 1995; Steffensmeier et al., 1998). Also, the other offense types found within the data - public order offenses, other felony, and misdemeanors -were omitted from the analyses due to the relatively small number of these compared to the other types of offenses. The other offense characteristic was the total number of charges against the defendant, as this could affect case outcome (see Williams, 2002; Hartley, Miller, \& Spohn, 2010). This was coded as a continuous variable (TotChrgs).

Other independent variables are not offender or case characteristics exclusively. The defendant's criminal justice status at the time of the offense was included to determine if being on probation, pa-role, etc. affected the outcome variables. In Florida (and other states), criminal justice status is a key sentencing variable; thus, an active status will affect a bail decision and the sentence given to a defendant. In Florida, an "active" legal status includes defendants with a number of characteristics, including escapes from custody, failures to appear, in custody, under pretrial diversion, or under community supervision (see Florida Department of Corrections, 2012). These statuses were included in the current data, combined, and were coded as $0=$ active, 1 = non-active (Status) (see Hartley, Miller, \& Spohn, 2010). Whether or not an individual was released or detained prior to adjudication was also included. Williams (2002) found that bail status was an important predictor of case outcome, in that those detained prior to case disposition were more likely to be incarcerated and to be given a longer sentence. This was supported by Turner and Johnson (2007), Kalhous and Meringolo (2012), and Miller and Guggenheim (1990). This was coded as $0=$ not detained, $1=$ detained (BailDet). Note that BailDet is also utilized as a dependent variable, as mentioned above. Due to this, BailDet as an independent variable was not included in analyses when assessing BailDet as a de-pendent variable. The defendant's prior convictions were included; this assessed the total number of convictions (felony or misdemeanor) and was coded as a continuous variable (Priors). As with criminal justice status, prior convictions are key variables affecting the sentence given to a defendant (see Hartley, Miller, \& Spohn, 2010; Williams, 2002). Finally, the number of days between arrest and adjudication was included. Some researchers indicate that a lengthy delay in case processing benefits defendants in that prosecutors are more likely to drop charges (see Hermann et al., 1977; National Center for State Courts, 1992; Williams, 2002). This was coded as a continuous variable (CaseLength).

\section{Results}

Table 1 provides the frequencies of the variables in the analyses. Regarding the pre-conviction dependent variables, just under a third of defendants (30\%) had their charges dismissed. Bail was offered to the vast majority of defendants (93\%), although only about one third (33\%) were released prior to case outcome. This suggests that many defendants could not afford to be released. Regarding the conviction variables, only a small percentage of defendants had their 
charges reduced to misdemeanors (8\%), and a majority of defendants was convicted (66\%). Of those who were convicted, only a small percentage was sent to prison (17\%) and, of these, the median sentence length was 24 months. The median was used here to counteract the effect of a small number of defendants sentenced to rather long prison terms.

Regarding the primary independent variable, Atty, most defendants had public defenders (83\%) as opposed to retained counsel. Most defendants were male (79\%), with a mean age of 33. Of the three race categories, most defendants in the sample were Black (46\%), followed by White (29\%), and Hispanic (25\%). Most defendants were not active at the time of their arrest (84\%), and the mean number of prior felony convictions was 3.25. The median number of days from arrest to adjudication was 105 , with a small percentage of defendants with disposition dates over a year or still pending (13\%). Finally, defendants were charged almost equally with violent (25\%), property (26\%), and drug (37\%) offenses.

\section{Table 1}

\section{Variables in the analyses}

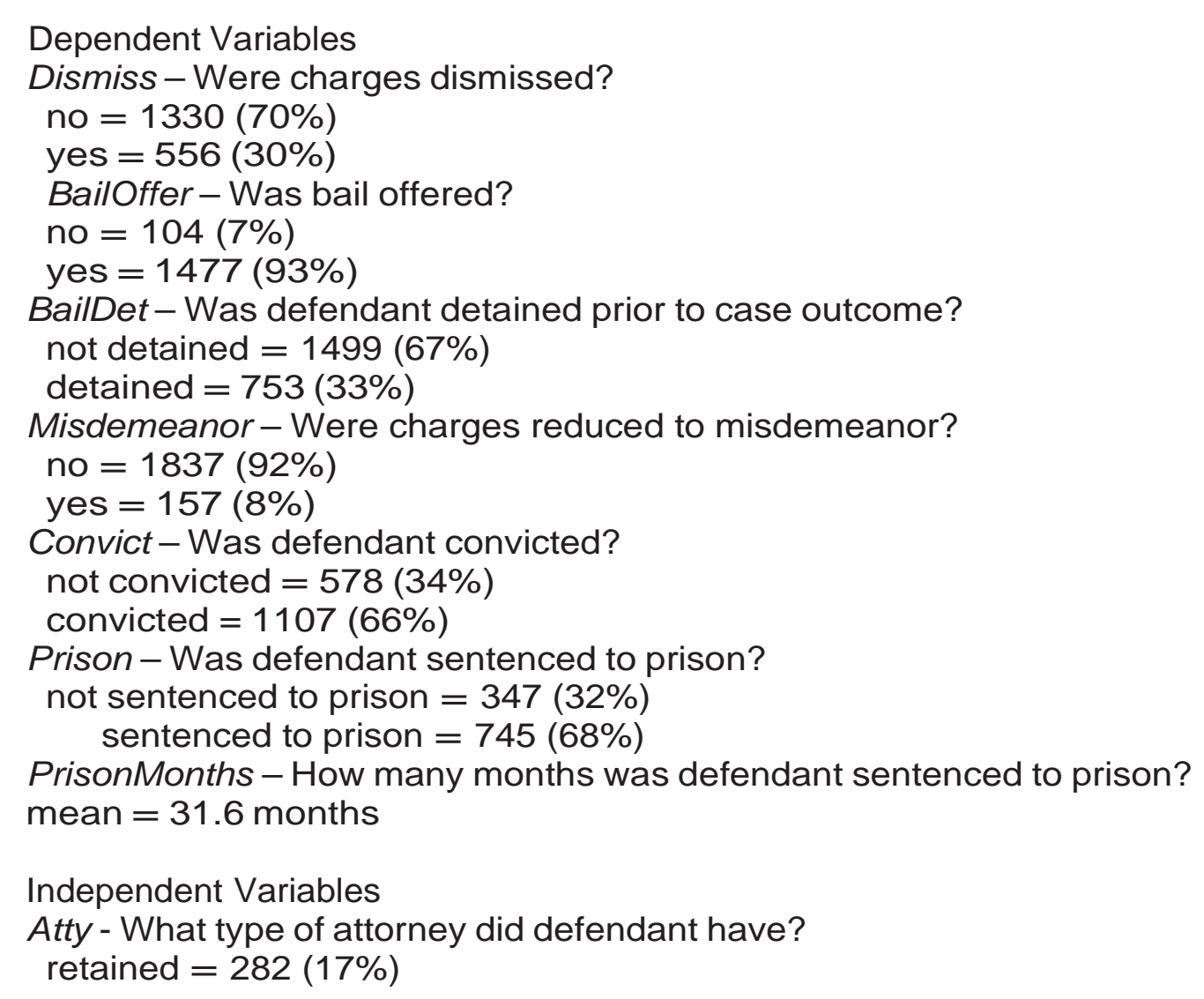




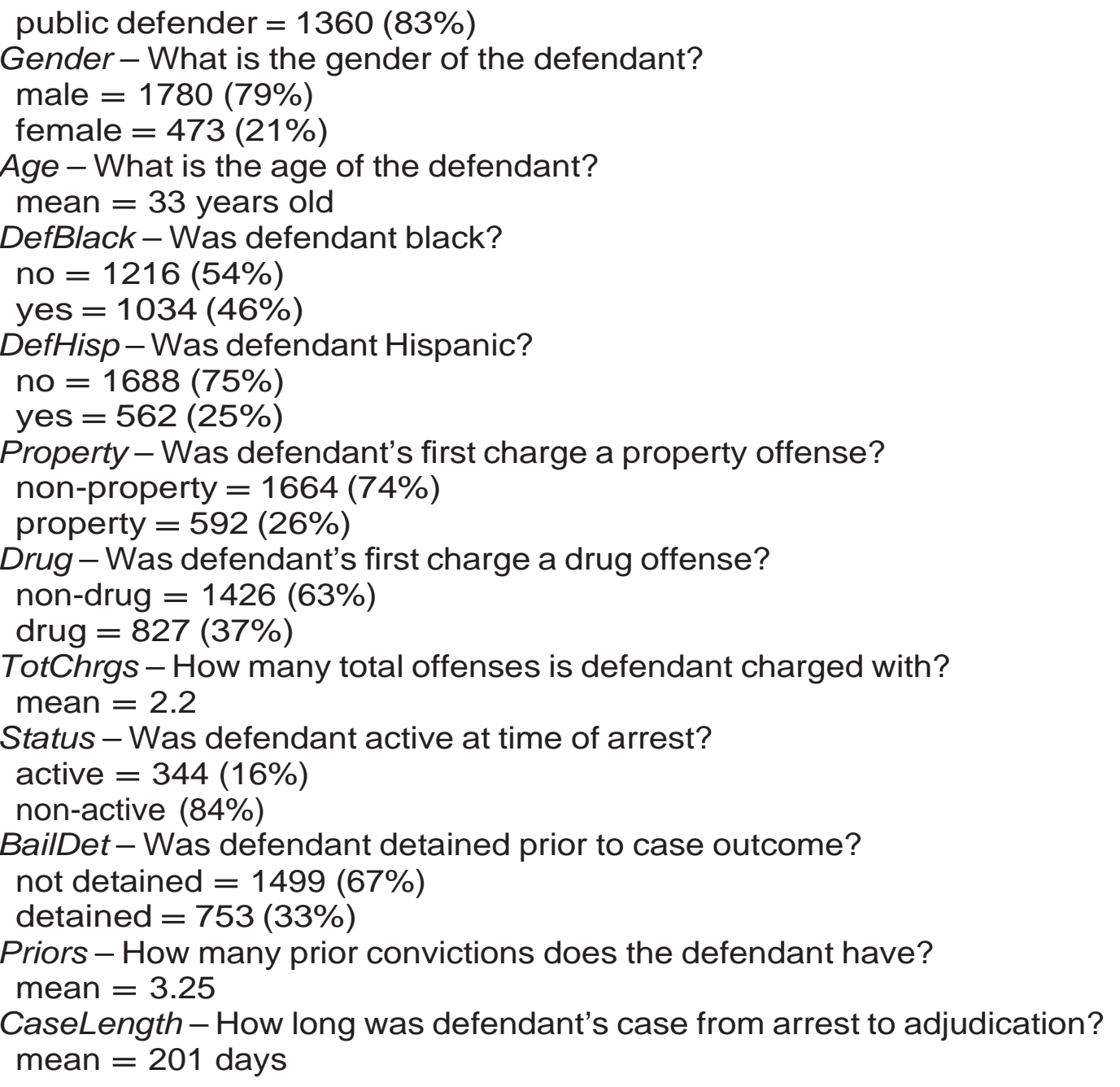

Each hypothesis was tested and the results are featured here as they were introduced earlier. It should be noted that, due to the use of four Florida counties, dummy variables for the counties were included in the analyses to account for any differences between counties.

Results for pre-conviction variables

Table 2 provides the results for the pre-conviction dependent variables of Dismiss, BailOffer, and BailDet. For Dismiss, BailOffer, and BailDet, logistic regression analysis was utilized due to the dichotomous nature of these variables. For Dismiss, type of attorney was significant, in that defendants with public defenders were less likely to get their charges dismissed ( $p$ b .01, odds ratio $=.561$ ). Although no hypothesis was offered for this relationship, this result supports research by Taylor et al. (1973) and Hanson and Ostrom (1998). Both property offenders ( $p$ b .01 , odds ratio $=.508)$ and drug of-fenders $(\mathrm{p} \mathrm{b} .01$, odds ratio $=.355)$ were less likely to have their charges dismissed compared to violent offenders. Defendants with more charges against them $(p$ b .01, odds ratio $=.781)$, with longer adjudication times $(p$ b .01, odds ratio $=.992)$, and who were detained prior to case outcome $(p$ b .01, odds ratio $=.522)$ were also less likely to have their charges dismissed. 
For BailOffer, type of attorney was not significant, indicating that there is no relationship between type of attorney and whether or not bail was offered to defendants. This supports hypothesis \#1.One significant variable is gender, in that females are more likely to be offered bail than males ( $p$ b .05, odds ratio $=2.155$ ). Other significant variables reflect case characteristics. Defendants charged with property $(p$ b .01, odds ratio $=2.107)$ and drug $(p b$ .01 , odds ratio $=2.555$ ) offense were more likely to be offered bail than defendants charged with vio-lent offenses. 1 Also, defendants with more charges against them were less likely to be offered bail $(\mathrm{p} \mathrm{b} .01$, odds ratio $=.721)$ and defendants whose status was not active at the time of arrest were more likely to be offered bail ( $p$ b .01, odds ratio $=5.599$ ).

For BailDet, type of attorney was significant, in that defendants with public defenders were more likely to be detained prior to case outcome than defendants with retained counsel ( $p$ b .01, odds ratio = 2.583). This supports hypothesis \#2. Females were less likely to be detained than males ( $p$ b .01, odds ratio $=.608$ ). As with BailOffer, a number of case characteristics variables were significant. Defendants with more charges against them are more likely to be detained prior to case outcome ( $\mathrm{p} \mathrm{b} .01$, odds ratio =1.347), as are defendants with multiple prior felony convictions ( $p$ b .01, odds ratio $=1.131$ ). Finally, defendants who were not active at the time of their arrest were less likely to be detained prior to case outcome ( $p$ b .01, odds ratio $=.423$ ).

These results somewhat contradict the findings of Hartley, Miller, and Spohn (2010). Although these authors combined the two bail variables into one (see description above), their results found no relationship between type of attorney and the bail decision.

\section{Results for conviction variables}

Table 3 provides the results for the dependent variables dealing with conviction. For the variables Misdemeanor, Convict, and Prison, due to the dichotomous nature of these variables, logistic regression analysis was used. For Misdemeanor, type of attorney was not significant. This supports hypothesis \#4. As for the other variables, none are significant. Although Hartley, Miller, and Spohn (2010) assessed whether the primary charge was reduced, not whether it was reduced to a misdemeanor, they also did not find a significant relationship with type of attorney.

For Convict, type of attorney was significant, in that defendants with public defenders were more likely to be convicted than defendants with retained counsel ( $p$ b .01, odds ratio $=1.768$ ). This does not support hypothesis \#5. For the other variables, defendants charged with proper-ty offenses $(p$ b .01, odds ratio $=1.556)$ and drug offenses $(p$ b .01, odds ratio $=3.637$ ) were more likely to be convicted than defendants charged with violent offenses. Additionally, defendants with more charges against them $(p$ b .01, odds ratio $=1.200)$, with more prior felony convictions $(p$ b .01, odds ratio $=1.049)$, and longer adjudication times $(p$ b .01, odds ratio $=1.006)$ are more likely to be convicted. Finally, defendants who are detained prior to case outcome are also more likely to be convicted than defendants who are released ( $p$ b .01, odds ratio $=1.732$ ). 


\begin{tabular}{|c|c|c|c|c|c|c|c|c|c|}
\hline & \multicolumn{3}{|l|}{ Dismiss } & \multicolumn{3}{|l|}{ Bailoffer } & \multicolumn{3}{|c|}{ BailDet } \\
\hline & \multicolumn{3}{|c|}{ (Logistic Regression) } & \multicolumn{3}{|c|}{ (Logistic Regression) } & \multicolumn{3}{|c|}{ (Logistic Regression) } \\
\hline & B & S.E. & $\operatorname{Exp}(B)$ & B & S.E. & $\operatorname{Exp}(B)$ & B & S.E. & $\operatorname{Exp}(B)$ \\
\hline Atty & -.578 & .195 & $.561^{* *}$ & -.424 & .326 & .654 & .949 & .184 & $2.583^{* *}$ \\
\hline Gender & .033 & .187 & 1.034 & .768 & 372 & $2.155^{*}$ & -.497 & .157 & $.608^{* *}$ \\
\hline Age & -.004 & .007 & .996 & .013 & .010 & 1.013 & .005 & .005 & 1.005 \\
\hline DefBlack & .010 & .179 & 1.010 & -.143 & .299 & .867 & -.215 & .146 & .807 \\
\hline DefHisp & -.112 & .211 & .894 & -.291 & .329 & .747 & .005 & .168 & 1.005 \\
\hline Property & -.678 & .178 & $.508^{* *}$ & .745 & .281 & $2.107^{* *}$ & .115 & .148 & 1.122 \\
\hline Drug & -1.037 & .185 & $.355^{* *}$ & .938 & .266 & $2.555^{* *}$ & -.029 & .137 & .971 \\
\hline BailDet & -.650 & .168 & $.522^{* *}$ & & & & & & \\
\hline TotChrgs & -.248 & .058 & $.781^{* *}$ & -.327 & .066 & $.721^{* * *}$ & .298 & .045 & $1.347^{* *}$ \\
\hline Status & .111 & .196 & $1.118^{* *}$ & 1.723 & .229 & $5.599^{* *}$ & -.861 & .150 & $.423^{* *}$ \\
\hline Priors & -.005 & .021 & .995 & -.001 & .031 & .999 & .123 & .016 & $1.131^{* *}$ \\
\hline CaseLength & -.008 & .001 & $.992^{* *}$ & -.001 & .001 & .999 & -.005 & .001 & $.995^{* *}$ \\
\hline -2 Log Likelihood & 1160.835 & & & 631.717 & & & 1807. & & \\
\hline Nagelkerke $\mathrm{R}^{2}$ & .46 & & & .21 & & & .23 & & \\
\hline $\mathrm{n}$ & 1233 & & & 1581 & & & 1593 & & \\
\hline
\end{tabular}

For defendants who were convicted, Prison was assessed to deter-mine if they were sentenced to prison. Type of attorney was not significant for this variable, which supports hypothesis \#6 and the results from Hartley, Miller, and Spohn (2010) and Williams (2002). For the other variables, females were less likely to be sentenced to prison ( $p$ b .01, odds ratio $=.263$ ). However, defendants with more charges against them ( $p$ b .01, odds ratio $=1.185$ ), with more prior felony convictions $(p$ b .01, odds ratio $=1.065)$, with longer disposition times $(p b .01$, odds ratio $=1.009)$, and who were detained prior to case outcome ( $p$ b .01, odds ratio $=4.736$ ) were more likely to be sentenced to prison.

Finally, PrisonMonths, was examined to assess the number of months defendants were sentenced to prison. Due to the continuous nature of this variable, OLS regression was used. Type of attorney was not significant for this variable, which supports hypothesis \#6, Hartley, Miller, and Spohn (2010), and Williams (2002). The only significant variables were Property and Drug, in that defendants sentenced to prison for either property ( $\mathrm{b} .01, \mathrm{~b}=-.226, \mathrm{t}=-2.651$ ) or drug ( $p$ b .01, $b=-.236, t=-.2651$ ) offenses were given fewer months in prison than defendants sentenced to prison for violent offenses.

\section{Discussion}

The right to appointed counsel has been in effect in all states since 1932, but it remains to be seen if appointed counsel is up to the task of providing effective assistance of counsel. Appointed counsel, and public defenders in particular, struggle with caseload and workload issues and this can affect the type of counsel provided by these defenders. The present study attempted to expand upon research by Williams (2002) and Hartley, Miller, and Spohn (2010) on the effectiveness of public defenders compared to retained counsel in Florida courts. The present study, examining multiple counties over the course of a year, found both similar and different results than the previous studies. Overall, all but one of the hypotheses posited in the present study were supported.

Although no hypothesis was proffered for the relationship be-tween type of attorney and the likelihood of dismissal of charges, results indicated that defendants with public defenders were less likely to have their charges dismissed. This result remained even when controlling for 
factors such as the seriousness of the offense and the total number of charges against a defendant. It could very well be that the evidence against these defendants was quite strong, but this was not measured in this data. Nonetheless, the results suggest that perhaps public defenders are not as effective at arguing for dismissal compared to their retained counterparts.

Table 3

Results for conviction variables

\begin{tabular}{|c|c|c|c|c|c|c|c|c|c|c|c|}
\hline & \multicolumn{3}{|c|}{ MISDEMEANOR } & \multicolumn{3}{|c|}{ CONVICT } & \multicolumn{3}{|l|}{ PRISON } & \multicolumn{2}{|c|}{ PRISONMONTHS } \\
\hline & \multicolumn{3}{|c|}{ (Logistic Regression) } & \multicolumn{3}{|c|}{ (Logistic Regression) } & \multicolumn{3}{|c|}{ (Logistic Regression) } & \multicolumn{2}{|c|}{ (OLS Regression) } \\
\hline & B & S.E. & $\operatorname{Exp}(B)$ & B & S.E. & $\operatorname{Exp}(B)$ & B & S.E. & $\operatorname{Exp}(B)$ & B & S.E. \\
\hline Atty & -.038 & .267 & .963 & .570 & .168 & $1.768^{* *}$ & -.241 & .254 & .786 & -5.239 & 5.527 \\
\hline Gender & .090 & .264 & 1.094 & -.166 & .155 & .847 & -1.335 & .349 & $.263^{* *}$ & 1.311 & 8.584 \\
\hline Age & .003 & .010 & 1.003 & .022 & .006 & 1.002 & .003 & .009 & 1.003 & -.257 & .228 \\
\hline DefBlack & .034 & .240 & 1.035 & .011 & .154 & 1.011 & -.033 & .230 & .968 & -1.375 & 5.119 \\
\hline DefHisp & -.044 & .315 & .957 & .032 & .174 & 1.032 & -.277 & .280 & .758 & 4.085 & 6.488 \\
\hline Property & -.289 & .267 & .749 & .442 & .148 & $1.556^{* *}$ & .201 & .238 & 1.222 & -13.690 & $5.164^{* *}$ \\
\hline Drug & -.275 & .249 & .759 & 1.291 & .150 & $3.367^{* *}$ & -.480 & .230 & $.619^{*}$ & -13.969 & $5.269^{* *}$ \\
\hline BailDet & -.269 & .243 & .764 & .549 & .135 & $1.732^{* *}$ & 1.555 & .223 & $4.736^{* *}$ & 7.235 & 4.768 \\
\hline TotChrgs & -.068 & .085 & .935 & .182 & .050 & $1.200^{* *}$ & .169 & .063 & $1.185^{* *}$ & 1.762 & 1.314 \\
\hline Status & .020 & .272 & 1.020 & -.233 & .167 & .792 & -.015 & .228 & .985 & 2.540 & 5.235 \\
\hline Priors & .032 & .028 & 1.033 & .048 & .017 & $1.049^{* *}$ & .063 & .026 & $1.065^{*}$ & -.415 & .582 \\
\hline CaseLength & .001 & .001 & 1.001 & .006 & .001 & $1.006^{* *}$ & .009 & .001 & $1.009^{* *}$ & .007 & .024 \\
\hline -2 Log Likelihood/Nagelkerke $\mathrm{R}^{2}$ & \multicolumn{3}{|c|}{$654.441 / .21$} & \multicolumn{3}{|c|}{$1682.192 / .26$} & \multicolumn{3}{|c|}{$739.221 / .27$} & & \\
\hline Adjusted $\mathrm{R}^{2}$ & & & & & & & & & & & \\
\hline $\mathbf{n}$ & \multicolumn{3}{|l|}{1593} & \multicolumn{3}{|l|}{1554} & \multicolumn{3}{|l|}{1006} & \multicolumn{2}{|l|}{745} \\
\hline
\end{tabular}

${ }^{* *} \mathrm{p}<.01 ;{ }^{*} \mathrm{p}<.05$.

The hypotheses surrounding the three pre-conviction variables were all supported in the analyses. Results indicated that there was no relationship between type of attorney and the likelihood of bail being offered, but this may be due to the fact that the vast majority of defendants (93.4\%) were offered bail, so the type of attorney may not have mattered here. However, defendants with public defenders were less likely to be released. These findings could be a function of the fact that defendants with public defenders are indigent; therefore, judges requiring a bail amount to be paid would make it difficult for such defendants to attain release.

For the control variables, it appears that both legal and extralegal variables affect case outcome. In particular, defendants with more charges against them, more prior convictions, and an active status at arrest were treated unfavorably by the courts. Prior convictions and status are key variables that judges take into account when making decisions, especially in Florida, so these results should not be surprising (see Hartley, Miller, \& Spohn, 2010). Regarding extralegal variables, gender was significant in some analyses, with all indicating that females were treated more favorably than males. This supports research by Crow and Gertz (2009) and Turner and Johnson (2006).

Of the hypotheses surrounding the four conviction variables, only one was not supported. Hypotheses \#4 suggested that there was no relationship between type of attorney and likelihood of conviction. Results indicated otherwise. In this study, defendants with public de-fenders were more likely to be convicted than defendants with retained counsel. This could be a function of earlier decisions within the process. As stated above, defendants with public defenders receive unfavorable bail decisions and this can impact whether a defendant is convicted. As stated earlier, one's bail status (i.e., being detained) increases the likelihood that a defendant will be convicted. Kalhous and Meringolo (2012) indicate that inability to make bail, "precludes the 
effective exercise" of other rights within the criminal justice system (p. 800). In particular, defendants are less able to assist in their own defense, meet with their attorneys, or assist in their investigation (Turner \& Johnson, 2007). Due to this, these defendants are more likely to be convicted (Albonetti, 1991).

Regarding the other conviction variables, all other hypotheses were supported. There was no relationship between type of attorney and the likelihood of reducing the charge to a misdemeanor. Again, like with the bail decision, only a small percentage of defendants had their charges reduced to a misdemeanor (7.9\%), so this could affect this result. There was also no relationship between type of attorney and the likelihood of a prison sentence and, if sentenced to prison, the length of sentence. This could be due to what Williams (2002) described as the result of sentence guidelines, which, "... require judges to impose certain sanctions, and the defense attorney has little power to present favorable deals..." (p. 255).

As for the control variables in the analyses of conviction variables, results were similar to the ones found for the pre-conviction analyses. Legal factors such as prior convictions and status at the time of arrest played a role in convictions, but so did the extralegal factor of gender. Again, it appears that females are treated more leniently than males, even in the era of sentence guidelines.

One of the reasons for the unfavorable results for public defenders could be caseload issues. This study examined four of the largest counties in Florida, suggesting that a higher number of cases in these counties could be contributing to pressures by public defenders to cut corners or make hasty decisions. This could not be examined, of course, so this is just speculation. However, given the state of public defense articulated by Babb (2000), perhaps Florida public defenders could benefit from increased funding. Lefstein (2011) states that the biggest problem facing public defenders is the lack of funding, which then contributes to excessive caseloads. Increased funding could lead to increased resources such as more attorneys, more investigators, or higher salaries for existing public defenders. It could also allow for caseload caps for individual public defenders. However, increased funding is probably not feasible given the state of the economy in many states, Florida included.

Another possible solution could come in the form of litigation. In June 2012, the Florida Supreme Court heard arguments from the Miami-Dade Public Defender, who filed motions to reduce the caseloads of public defenders in his county. He argued that the Florida Legislature had continued to cut funding despite the fact that more cases were flooding the defender offices. It was argued that excessive caseloads prevent public defenders from providing the quality of counsel guaranteed by the Sixth Amendment of the U.S. Constitution as well as the model standards set forth by the American Bar Association. As of this writing, the court has not issued a ruling (see Saunders, 2012).

One of the limitations of the current study is generalizability. As with any research study, the focus on one state or even multiple counties within a state means that results are not generalizable to all states or even other counties within one state. However, the current research is consistent with previous research on public defenders that only focuses on one geographic area. Another limitation is that the current study could not examine actual caseload numbers; there-fore, any conclusions about excessive caseloads driving the results is purely speculative. However, given the evidence from Babb (2000) and the Miami Public Defender, it 
would appear that caseloads are at least partly responsible for some of the results found in the current study.

Future research needs to continue to examine this issue. It is critical that indigent defendants are afforded the promise of the Gideon decision to have case outcomes that reflect "fundamental fairness" in their proceedings. As Williams (2002) noted, the state of Florida has an above-average public defender system, so results that indicate that the representation provided by these defenders is not the same as retained counsel provides a troubling picture of indigent defense in state courts.

\section{Note}

1. Based on comments from a reviewer, it should be noted that, in Florida, capital murders may be denied bail automatically, though this is not always the case. The cur-rent data did not differentiate between capital murders and other murders, so singling out capital murders was not possible. Therefore, analyses for BailOffer and BailDet were conducted which excluded all murders from the "violent" category of offenses to deter-mine if murders could skew the results. Results indicated that excluding murders from the "violent" category of offenses did not alter the results.

\section{References}

Albert-Goldberg, N., \& Hartman, M. (1983). Public defender in America. In W. McDonald (Ed.), The defense counsel (pp. 67-102). Beverly Hills: Sage Publications. Albonetti, C. (1991). An integration of theories to explain judicial discretion. Social Problems, 38, 247-266.

Anderson, J., \& Heaton, P. (2012). How much difference does the lawyer make? The effect of defense counsel on murder case outcomes. Yale Law Journal, 122, 154-187. Babb, H. (2000). A Florida perspective on public defenders. Retrieved from http://www. pbs.org/wgbh/pages/frontline/shows/bostonda/elsewhere/babb.html

Blumberg, A. (1967). The practice of law as a confidence game: Organization and cooptation of a profession. Law and Society Review, 1, 15-39.

Calogero, P. (1995). The right to counsel and indigent defense. Loyola Law Review, 41, 265290.

Champion, D. (1989). Private counsels and public defenders: A look at weak cases, prior records, and leniency in plea bargaining. Journal of Criminal Justice, 17, 253-263.

Crow, M., \& Gertz, M. (2009). Sentencing policy and disparity: Guidelines and the influence of legal and democratic cultures. Journal of Criminal Justice, 36, 362-371.

Daly, K. (1987). Structure and practice of familial-based justice in a criminal court. Law and Society Review, 21, 267-284.

Eisenstein, J., Fleming, R., \& Nardulli, P. (1987). The contours of justice: Communities and their courts. Boston, MA: Little, Brown and Company.

Farrell, R., \& Swigert, V. (1978). Prior offense record as a self-fulfilling prophecy. Law and Society Review, 12, 437-453. 
Florida Department of Corrections (2012). Florida criminal punishment code: Score preparation worksheet. Retrieved from http://www.dc.state.fl.us/pub/sen_cpcm/ cpc_manual.pdf

Garcia, A. (1992). The First Amendment in modern American jurisprudence. New York, NY: Greenwood Press.

Gitelman, M. (1971). The relative performance of appointed and retained counsel in Arkansas felony cases: An empirical study. Arkansas Law Review, 24, 442-452.

Hanson, R., \& Ostrom, B. (1998). Indigent defenders get the job done and done well. In G. Cole $\&$ M. Gertz (Eds.), The criminal justice system: Politics and policies (pp. 264-288). Belmont, CA: Wadsworth.

Hartley, R., Miller, H., \& Spohn, C. (2010). Do you get what you pay for? Type of counsel and its effect on criminal court outcomes. Journal of Criminal Justice, 38, 1063-1070.

Hermann, R., Single, E., \& Boston, J. (1977). Counsel for the poor. Boston, MA:

Lexington Books.

Hoffman, M., Rubin, P., \& Shepherd, J. (2005). An empirical study of public defender effectiveness: Self-selection by the "marginally indigent". Ohio State Journal of Criminal Law, 3, 223-255.

Holmes, M., Hosch, H., Daudistel, H., Perez, D., \& Graves, J. (1996). Ethnicity, legal resources, and felony dispositions in two southwestern jurisdictions. Justice Quarterly, 13, 1130.

lyengar, R. (2010). An analysis of the performance of federal indigent defense counsel. NBER Working Paper Series, 13187, (Retrieved from www.nber.org/papers/w13187).

Joy, P. (2010). Ensuring the ethical representation of clients in the face of excessive caseloads. Missouri Law Review, 75, 771-792. Justice Policy Institute (2011). System overload: The costs of under-resourcing public defense.

Justice Policy Institute (Retrieved from

http://www.justicepolicy.org/ uploads/justicepolicy/documents/system_overload_final.pdf)

Kalhous, C., \& Meringolo, J. (2012). Bail pending trial: Changing interpretations of the Bail Reform Act and the importance of bail from defense attorneys' perspectives. Pace Law Review, $32,800-855$.

Lefstein, N. (2001). Securing reasonable caseloads: Ethics and law in public defense. (Retrieved from http://www.americanbar.org/content/dam/aba/publications/books/ ls_sclaid_def_securing_reaso nable_caseloads.authcheckdam.pdf)

Lehtinen, M., \& Smith, G. (1974). The relative effectiveness of public defenders and private attorneys. NLADA Briefcase, 33, 13-19. 
Liang, B., Long, M., \& Brame, W. (2012). Is it legal representation or clients? An empirical testing of clients' performance and their legal representation in Tulsa County drug and dui programs. American Journal of Criminal Justice, 37, 544-561.

Miller, M., \& Guggenheim, M. (1990). Pretrial detention and punishment. Minnesota Law Review, 75, 335-426.

Nagel, S. (1973). Effects of alternative types of counsel on criminal procedural treatment. Indiana Law Journal, 48, 404-426.

Nardulli, P. (1986). Insider justice: Defense attorneys and the handling of felony cases. The Journal of Criminal Law and Criminology, 77, 379-417.

National Center for State Courts (1992). Indigent defenders: Get the job done and done well. Washington, DC: National Center for State Courts.

Neubauer, D., \& Fradella, H. (2011). America's courts and the criminal justice system. Independence, KY: Cengage.

Office of Justice Programs (2011). Fact sheet: Indigent defense. Office of Justice Programs, U.S. Department of Justice (Retrieved from http://www.ojp.usdoj.gov/ newsroom/factsheets/ojpfs_indigentdefense.html)

Ogletree, C. (1995). An essay on the new public defender for the 21st century. Law and Contemporary Problems, 58, 81-93.

Saunders, J. (2012, June 7). Florida Supreme Court hears Miami-Dade public defender's case. Miami Herald. Retrieved from http://www.miamiherald.com/2012/06/07/ 2837637/floridasupreme-court-hears-miami.html

Silverstein, L. (1965). Defense of the poor in criminal cases in America state courts: A field study and report. Chicago, IL: American Bar Association.

Skolnick, J. (1967). Social control in the adversary system. Journal of Conflict Resolution, 11, 52-70.

Smith, S., \& DeFrances, C. (1996). Indigent defense. Washington, DC: U.S. Department of Justice (Retrieved from http://bjs.ojp.usdoj.gov/content/pub/pdf/id.pdf)

Spangenberg Group. (2001). Keeping defender workloads manageable. Spangenberg Group (Retrieved from http://www.spangenberggroup.com/pub.html)

Spangenberg Group. (2009). Assessment of theWashoe and Clark County, Nevada public defender offices final report. Center for Justice, Law, and Society at GeorgeMason University (Retrieved from http://www.nevadajudiciary.us/index.php/viewdocumentsand forms/func-startdown/2033/)

Spohn, C., \& Holleran, D. (2000). The imprisonment penalty paid by young, unemployed, black and Hispanic male offenders. Criminology, 38, 281-306. 
Spohn, C., \& Katz, C. (1995). The effect of race and gender on bail outcomes: A test of an interactive model. American Journal of Criminal Justice, 19, 161-184.

Steffensmeier, D., Ulmer, J., \& Kramer, J. (1998). The interaction of race, gender, and age in criminal sentencing: The punishment cost of being young, black, and male. Criminology, 36, 763-798.

Stover, R., \& Eckhart, D. (1975). A systematic comparison of public defenders and private attorneys. American Journal of Criminal Law, 3, 265-300.

Taylor, J., Stanley, T., DeFlorio, B., \& Seekamp, L. (1973). An analysis of defense counsel in the processing of felony defendants in Denver, CO. Denver Law Journal, 50, 1-40.

Turner, K., \& Johnson, J. (2003). The impact type of attorney has on the judicial decision of bail. Criminal Law Bulletin, 39, 426-444.

Turner, K., \& Johnson, J. (2006). Effects of gender on the judicial decision of bail amount set. Federal Probation, 70, 56-62.

Turner, K., \& Johnson, J. (2007). The relationship between type of attorney and bail amount set for Hispanic defendants. Hispanic Journal of Behavioral Sciences, 29, 384-400.

U.S. Department of Justice. Bureau of Justice Statistics. (2006). State court processing statistics, 1990-2006. [Computer file]. Conducted by Pretrial Services Resource Center [Producer]. ICPSR02038 - v.2. Ann Arbor, MI: Inter-University Consortium for Political and Social Research [Distributor].

Uphoff, R. (1992). The criminal defense lawyer: Zealous advocate, double agent, or beleaguered dealer? Criminal Law Bulletin, 28, 419-456.

Walker, S., Spohn, C., \& DeLone, M. (2004). The color of justice: Race, ethnicity, and crime in America. Toronto, ON: Wadsworth. Weitzer, R. (1996). Racial discrimination in the criminal justice system: Findings and problems in the literature. Journal of Criminal Justice, 24, 309322.

Wice, P. (2005). Public defenders and the American justice system. Santa Barbara: Praeger. Williams, M. (2002). A comparison of sentencing outcomes for defendants with public defenders versus retained counsel in a Florida circuit court. Justice System Journal, 23, 249-257.

Wilson, D. (1984). The effects of counsel on the severity of criminal sentences: A statistical assessment. Justice System Journal, 9, 87-101.

Wolf-Harlow, C. (2000). Defense counsel in criminal cases. Washington, DC: U.S. Department of Justice (Retrieved from http://bjs.ojp.usdoj.gov/content/pub/pdf/dccc.pdf)

Court Cases

Argersinger v. Hamlin 407 U.S. 25 (1972).

Bennett v. State 605 So. 2d 552 (1992).

Denmark v. Florida 616 So. 2d 1104 (1993).

Gideon v. Wainwright 372 U.S. 335 (1963). 
Powell v. Alabama 287 U.S. 45 (1932).

Woods v. State 595 So. 2d 264 (1992). 